OPEN ACCESS

Edited by:

Manoj K. Sharma

Jawaharlal Nehru University, India

Reviewed by:

Anil Kumar Singh,

ICAR-Indian Institute of Agricultural

Biotechnology, India

Shri Ram Yadav,

Indian Institute of Technology,

Roorkee, India

*Correspondence:

Karaba N. Nataraja

nataraja_karaba@yahoo.com;

nnkaraba@uasbangalore.edu.in

Specialty section:

This article was submitted to

Plant Biotechnology,

a section of the journal

Frontiers in Plant Science

Received: 17 December 2016

Accepted: 10 March 2017

Published: 04 April 2017

Citation:

Sajeevan RS, Nataraja KN

Shivashankara KS, Pallavi N, Gurumurthy DS and Shivanna MB

(2017) Expression of Arabidopsis

SHN1 in Indian Mulberry (Morus indica L.) Increases Leaf Surface Wax

Content and Reduces Post-harvest

Water Loss. Front. Plant Sci. 8:418.

doi: 10.3389/fpls.2017.00418

\section{Expression of Arabidopsis SHN1 in Indian Mulberry (Morus indica L.) Increases Leaf Surface Wax Content and Reduces Post-harvest Water Loss}

\author{
R. S. Sajeevan ${ }^{1,2}$, Karaba N. Nataraja ${ }^{1 *}$, K. S. Shivashankara ${ }^{3}$, N. Pallavi ${ }^{1,}$ \\ D. S. Gurumurthy ${ }^{4}$ and M. B. Shivanna ${ }^{2}$
}

\begin{abstract}
${ }^{1}$ Department of Crop Physiology, University of Agricultural Sciences, Bangalore, India, ${ }^{2}$ Department of Studies in Applied Botany, Kuvempu University, Shimoga India, ${ }^{3}$ Division of Plant Physiology and Biochemistry, Indian Institute of Horticultural Research, Bangalore, India, ${ }^{4}$ ITC Life Sciences and Technology Centre, ITC Limited, Bangalore, India
\end{abstract}

Mulberry (Morus species) leaf is the sole food for monophagous silkworms, Bombyx mori L. Abiotic stresses such as drought, salinity, and high temperature, significantly decrease mulberry productivity and post-harvest water loss from leaves influence silkworm growth and cocoon yield. Leaf surface properties regulate direct water loss through the cuticular layer. Leaf surface waxes, contribute for cuticular resistance and protect mesophyll cells from desiccation. In this study we attempted to overexpress AtSHN1, a transcription factor associated with epicuticular wax biosynthesis to increase leaf surface wax load in mulberry. Agrobacterium mediated in vitro transformation was carried out using hypocotyl and cotyledonary explants of Indian mulberry (cv. M5). Mulberry transgenic plants expressing AtSHN1 displayed dark green shiny appearance with increased leaf surface wax content. Scanning electron microscopy (SEM) and gas chromatograph-mass spectrometry (GC-MS) analysis showed change in pattern of surface wax deposition and significant change in wax composition in AtSHN1 overexpressors. Increased wax content altered leaf surface properties as there was significant difference in water droplet contact angle and diameter between transgenic and wild type plants. The transgenic plants showed significant improvement in leaf moisture retention capacity even $5 \mathrm{~h}$ after harvest and there was slow degradation of total buffer soluble protein in detached leaves compared to wild type. Silkworm bioassay did not indicate any undesirable effects on larval growth and cocoon yield. This study demonstrated that expression of AtSHN1, can increase surface wax load and reduce the post-harvest water loss in mulberry.

Keywords: mulberry, AtSHN1, transgenic plants, epicuticular wax, post-harvest water loss, moisture retention capacity 


\section{INTRODUCTION}

Mulberry, a member of the family Moraceae is commercially cultivated as the sole source of food for monophagous silkworm, Bombyx mori L. Increase in mulberry productivity is vital for sericulture industry. India is the second largest producer of raw silk, next to Republic of China Central Silk Board, (2014-2015). To meet the silk demand, there is a need to increase mulberry leaf production. Major mulberry growing areas in India are under dry and irrigated conditions. Under these conditions, abiotic stresses such as drought, salinity, and alkalinity cause $50-60 \%$ yield loss (Rao, 2002). In addition to these constraints, post-harvest water loss due to the time lag between leaf harvest and silkworm feeding influences silkworm growth and cocoon yield (Mamrutha et al., 2010). Slow water loss from harvested leaves is a desirable trait, which helps in maintaining post-harvest leaf quality. Since stomata close soon after the leaves are detached, leaf surface waxes play a significant role in regulating moisture loss. The importance of leaf surface wax in regulating leaf moisture loss has been demonstrated and a positive correlation between surface wax load and moisture retention capacity (MRC) has been shown in mulberry (Mamrutha et al., 2010).

Leaf surface waxes are complex mixture of very-long-chain fatty acids and their derivatives, produced through complex biochemical pathways (Jenks et al., 1996, 2002; Samuels et al., 2008; Kunst and Samuels, 2009). Chemical characteristics of the cuticular wax, surface wax load, and wax crystal morphology are the primary determinants of the permeability of the plant cuticle (Schreiber et al., 1996; Mamrutha et al., 2010, 2017). Considerable progress has been made in understanding the genetic determinants of the biosynthesis of cutin and cuticular waxes in model plants (Kunst et al., 2006; Kunst and Samuels, 2009; Yeats and Rose, 2013; Lee and Suh, 2015a). A number of upstream regulatory proteins such as transcriptions factors (TFs) that coordinate the expression of downstream target genes associated with wax biosynthesis have been shown to alter leaf surface wax load (Broun et al., 2004; Seo et al., 2011; Borisjuk et al., 2014; Park et al., 2016). Many regulatory proteins, such as, SHINE1/Wax Inducer1 (SHN1/WIN1) in Arabidopsis thaliana (Aharoni et al., 2004; Broun et al., 2004), WXP1/2 in Medicago (Zhang et al., 2005, 2007), Outer Cell Layer 1 (OCL1) in Zea mays (Javelle et al., 2010), MYB96 in Arabidopsis and Camelina sativa (Seo et al., 2011; Lee et al., 2014), MYB94 in Arabidopsis (Lee and Suh, 2015b), MYB106 and MYB16 in Arabidopsis and Torenia fournieri, respectively (Oshima et al., 2013), have been shown to be associated with surface wax deposition. The SHN1/WIN1 proteins belonging to the APETALA2/ETHYLENE RESPONSE FACTOR (AP2/ERF) family are well known for their diverse functions including regulating plant developmental processes and imparting stress tolerance. The transgenic Arabidopsis plants overexpressing SHN1/WIN1 showed dark green, glossy leaves with approximately 4.5-fold increased accumulation of epicuticular waxes in stem and leaves (Broun et al., 2004; Aharoni et al., 2004). The AtSHN1 overexpressers showed improved tolerance to abiotic stresses (Aharoni et al., 2004; Broun et al.,
2004; Kannangara et al., 2007; Karaba et al., 2007a,b). In this study we generated transgenic mulberry plants constitutively expressing AtSHN1 and examined its effect on epicuticular wax load, composition and its impact on cuticular water loss. AtSHN1 overexpression increased leaf surface wax load and improved leaf MRC in mulberry.

\section{MATERIALS AND METHODS}

\section{Cloning of SHN1 from Arabidopsis thaliana}

Full length SHN1 (AT1G15360) ${ }^{1}$ was isolated from the genomic DNA of $A$. thaliana using high-fidelity DNA polymerase (Finnzymes, Finland). Genomic DNA was isolated from tender leaves using the cetyltrimethyl ammonium bromide (CTAB) method (Muhammad et al., 1994). The polymerase chain reaction (PCR) was performed in a gradient PCR system (Mastercycler, Eppendorf, Germany) using SHN1 specific forward and reverse primers (Supplementary Table 1). The amplified product was gel purified using GenElute ${ }^{\mathrm{TM}}$ gel extraction kit (Sigma, USA) and cloned into T/A (pTZ57R/T) cloning vector (MBI Fermentas, Hanover, MD, USA) and sequence verified (ABI 3730; Applied BioSystems, Foster City, CA, USA).

\section{Construction of AtSHN1 Overexpression Vector}

The full-length AtSHN1 was released from the pTZ57R/T:AtSHN1 plasmid by Sma1 and Sac1 restriction enzymes and sub-cloned into binary vector pBI121. The recombinant overexpression construct designated as pBI121-

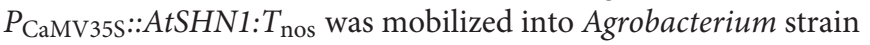
EHA105 by electroporation (Sambrook et al., 1989) and used for transformation. Agrobacterium was cultured in AB minimal medium supplemented with kanamycin $\left(50 \mathrm{mg} \mathrm{L}^{-1}\right)$, rifampicin (10 $\mathrm{mg} \mathrm{L}^{-1}$ ) and acetosyringone $(200 \mu \mathrm{M})$ for $18-20 \mathrm{~h}$ at $28^{\circ} \mathrm{C}$, at $230 \mathrm{rpm}$ in dark. Bacterial culture in its early log phase (optical density at $600 \mathrm{~nm}$ of $0.6-0.8$ ) was chosen for plant transformation.

\section{Mulberry Transformation and Regeneration}

The seeds of mulberry, Morus indica (cv. M5) harvested from fresh fruits were surface sterilized with $\mathrm{HgCl}_{2}(0.1 \%$, w/v) for $8 \mathrm{~min}$ and washed five to six times with sterile water. Seeds were imbibed overnight in sterile water were cultured on MS (Murashige and Skoog, 1962) medium in dark for 5-8 days before shifting to long-day culture conditions (16/8 h light/dark) at $26 \pm 2{ }^{\circ} \mathrm{C}$. Hypocotyls and cotyledons excised from 15 days old seedlings were used as explants for plant transformation.

Agrobacterium-mediated transformation protocol established by Bhatnagar and Khurana (2003) was followed to generate transgenic mulberry plants with minor modifications. Hypocotyl

\footnotetext{
${ }^{1}$ http://www.arabidopsis.org
} 
and cotyledon explants were pre-incubated for 5 days on MS medium containing thidiazuron (TDZ) $\left(0.1 \mathrm{mg} \mathrm{L}^{-1}\right)$. After Agrobacterium infection, the explants were incubated on MS medium containing TDZ (1.1 $\left.\mathrm{mg} \mathrm{L}^{-1}\right)$ and acetosyringone (250 $\mathrm{mM}$ ) for 3 days in dark. Subsequently, the explants were cultured on MS medium containing TDZ $\left(0.1 \mathrm{mg} \mathrm{L}^{-1}\right)$, cefotaxime (200 $\left.\mathrm{mg} \mathrm{L}^{-1}\right)$, and kanamycin $\left(50 \mathrm{mg} \mathrm{L}^{-1}\right)$. To select transformed tissue, selection pressure [kanamycin $\left(50 \mathrm{mg} \mathrm{L}^{-1}\right)$ ] was applied for 45 days and healthy shoots were separated and transferred to rooting media containing indole butyric acid, (IBA, 0.5 and $\left.1.0 \mathrm{mg} \mathrm{L}^{-1}\right)$ in the presence $(1.0 \%, \mathrm{w} / \mathrm{v})$ or absence of activated charcoal. Well rooted plantlets were hardened on soilrite and healthy plantlets were transplanted into pots filled with potting mixture 2:1:1 (garden soil, sand, and farmyard manure), and allowed to grow in transgenic containment facility.

\section{Polymerase Chain Reaction (PCR) and RT-PCR Analysis}

Genomic DNA was isolated from leaves of wild type and four transgenic lines (35S S-L1, L2, L3 and L4) using the CTAB method (Muhammad et al., 1994). To confirm the presence of genes, PCR was performed using neomycin phosphotransferase II (NptII) and AtSHN1 gene-specific forward and reverse primers (Supplementary Table 1). Further, PCR was also performed using AtSHN1 forward and Nos terminator reverse primers (Supplementary Table 1). The identity of the amplified product was confirmed by sequencing (ABI 3730; Applied BioSystems, Foster City, CA, USA).

For transgene expression analysis, total RNA was isolated from leaf tissues (100 mg) collected from wild type and four transgenic lines (35S S-L1, L2, L3, and L4) using the modified lithium chloride precipitation method by Sajeevan et al. (2014). All samples were treated with DNase1 to remove genomic DNA contamination and about $4 \mu \mathrm{g}$ of total RNA was used as the template to synthesize cDNA using the RevertAid First Strand cDNA Synthesis Kit (MBI Fermentas, Hanover, $\mathrm{MD}$, USA). The first strand cDNA template was used to examine the expression of transgene using AtSHN1 gene-specific primers (Supplementary Table 1). The house keeping gene actin (Supplementary Table 1) was used as an internal control for all the PCR reactions. The RT-PCR products were separated by agarose gel electrophoresis (Sambrook et al., 1989), documented using gel documentation system (Herolab, Germany) and product intensities were quantified using ImageJ $1.45 \mathrm{~s}$ software ${ }^{2}$ and presented as relative expression.

\section{Southern Hybridization}

Transgene integration was assessed by Southern blot hybridization. Genomic DNA $(15 \mu \mathrm{g})$ was digested with HindIII restriction enzyme at $37^{\circ} \mathrm{C}$ overnight. The digested DNA was separated on $0.8 \%(\mathrm{w} / \mathrm{v})$ agarose gel and transferred to positively charged Hybond-N+ nylon membrane (Amersham, UK). For Southern blot, nptII gene fragment (790 bp) was PCR amplified using binary vector pBI121 as template and labeled with Digoxigenin-11-dUTP using DIG-High Prime

${ }^{2}$ http://imagej.nih.gov/ij
DNA labeling and detection kit (Roche Applied Science, catalog 11745832910) as per manufacturer's instructions. Probe labeling strength was quantified as per kit instructions. Prehybridization of blot was carried out at $60^{\circ} \mathrm{C}$ for $4 \mathrm{~h}$. Hybridization with denatured probe $(\sim 1000 \mathrm{ng})$ was carried out overnight at $60^{\circ} \mathrm{C}$. Post hybridization blot was washed twice for $15 \mathrm{~min}$ each at $60^{\circ} \mathrm{C}$; once with $2 \mathrm{X}$ Saline-Sodium Citrate (SSC) and $1 \%(\mathrm{w} / \mathrm{v})$ Sodium Dodecyl Sulphate (SDS) followed by another wash with 2X SSC and $0.5 \%(\mathrm{w} / \mathrm{v})$ SDS. Probe hybridization was detected by anti-DIG antibody conjugated with alkaline phosphatase using substrates nitroblue tetrazolium chloride (NBT) and 5-bromo4-chloro-3-indolyl-phosphate (BCIP) as per manufacturer's instructions.

\section{Epicuticular Wax Quantification}

Leaf surface waxes were extracted and quantified using a colorimetric method (Ebercon et al., 1977; Mamrutha et al., 2010). This method is based on the color change produced by the reaction of wax with acidic potassium dichromate $\left(\mathrm{K}_{2} \mathrm{Cr}_{2} \mathrm{O}_{7}\right)$. Carnauba wax (Sigma, USA) was used as a standard for leaf surface wax quantification (Samdur et al., 2003). Total leaf surface wax amount was expressed as $\mu \mathrm{g} \mathrm{dm}^{-2}$.

\section{Scanning Electron Microscopy (SEM)}

Scanning electron microscopy was used to study surface wax morphology on the adaxial and abaxial surfaces of mature leaves collected from two selected mulberry transgenic lines (35S S-L2 and L4) and wild type plant. Leaf tissue was fixed in 5\% (v/v) glutaraldehyde and mounted on stubs. Samples were coated with gold particles for $10 \mathrm{~min}$. Coated samples were transferred to an ESEM, Quanta 200 (FEI, USA) scanning electron microscope for examination (Chuong et al., 2006).

\section{Wax Extraction and Analysis of Wax Composition}

Leaf surface wax was extracted from mature leaves of two selected mulberry transgenic lines (35S S-L2 and L4) and wild type plant using chloroform for $15 \mathrm{~s}$ (Mamrutha et al., 2010). The leaf surface extracts contained waxes from both adaxial and abaxial leaf surfaces. Chloroform was evaporated and the dried wax was dissolved in hexane and injected to gas chromatographmass spectrometry (GC-MS) for analysis of the profile (Gutierrez et al., 1998). The analysis was performed on a Varian-3800 gas chromatograph coupled with Varian 4000 GC-MS/MS (Varian, USA) ion-trap mass selective detector. Wax compounds were separated on DB-5MS (Varian, USA) column $(30 \mathrm{~m} \times 0.25 \mathrm{~mm}$ i.d. with $0.25 \mu \mathrm{m}$ film thickness) using the temperature program with injector port temperature at $300^{\circ} \mathrm{C}$, column temperature program of $100^{\circ} \mathrm{C}$ for $2 \mathrm{~min}$; increasing at $6^{\circ} \mathrm{C} / \mathrm{min}$ to $244^{\circ} \mathrm{C}$, $2 \mathrm{~min}$ at $244^{\circ} \mathrm{C}$; increasing at $8^{\circ} \mathrm{C} / \mathrm{min}$ to $300^{\circ} \mathrm{C}$, and $30 \mathrm{~min}$ at $300^{\circ} \mathrm{C}$. Wax composition was determined by comparing peak retention times with those of reference standards (Pentadecane), and by a GC-MS analysis of representative samples. The mass spectrometer was operated in the external electron ionization mode with the carrier gas helium $1 \mathrm{ml} / \mathrm{min}$; injector temperature, $300^{\circ} \mathrm{C}$; trap temperature $200^{\circ} \mathrm{C}$, ion source-heating at $200^{\circ} \mathrm{C}$ and 

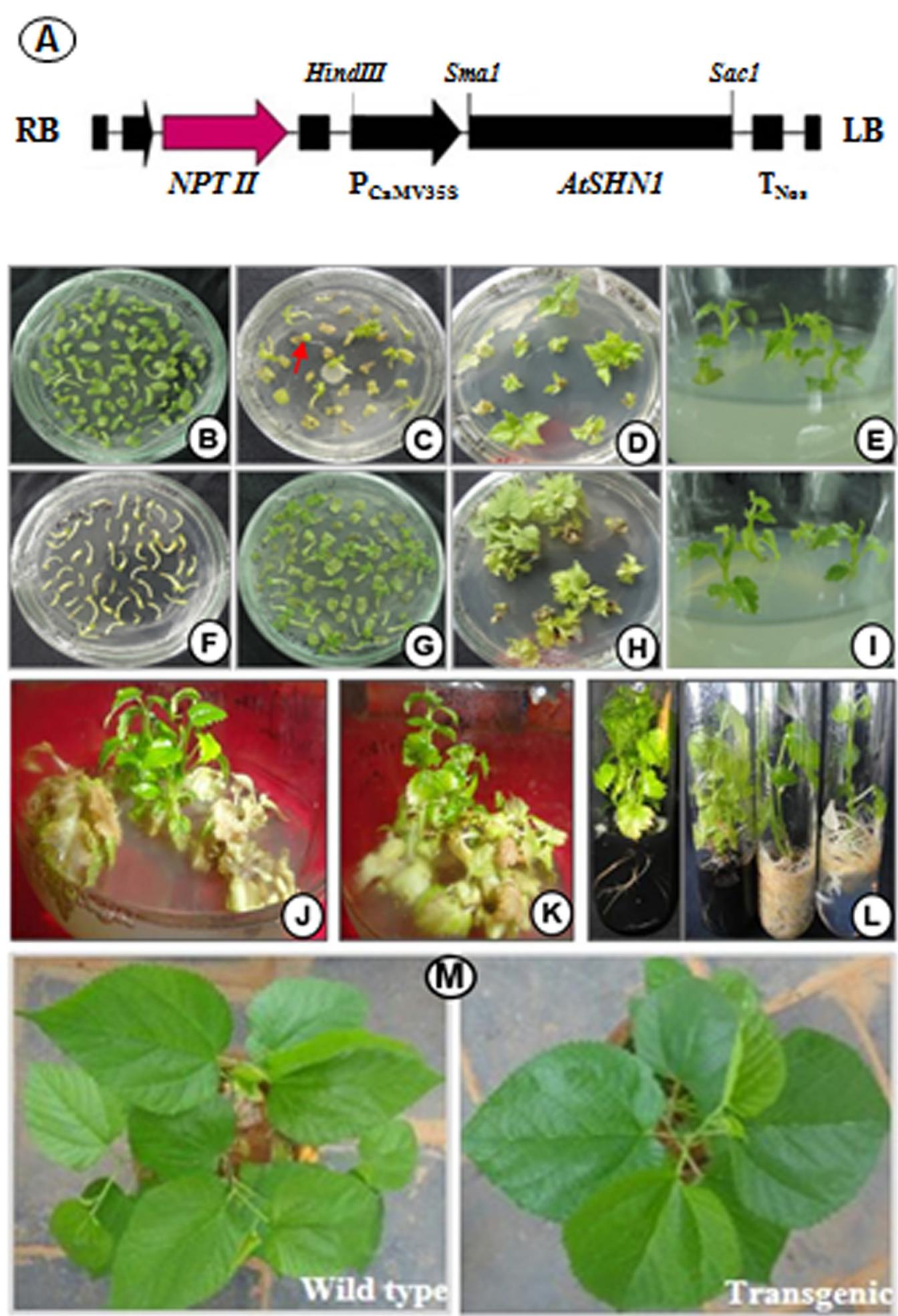

FIGURE 1 | Genetic transformation and development of mulberry transgenic plants to express AtSHN1. (A) schematic representation of T-DNA region of pBl121 carrying AtSHN1gene; (B) cotyledons separated from seedlings in pre-incubation medium; (C) emergence of shoots after the infection with Agrobacterium in selection medium with kanamycin $50 \mathrm{mg} \mathrm{L}^{-1}$; (D,E) regeneration of individual events in growth medium containing kanamycin $50 \mathrm{mg} \mathrm{L}^{-1}$; (F) hypocotyls separated from seedlings in pre-incubation medium; (G) emergence of shoots after the infection with Agrobacterium in selection medium with kanamycin 50 mg $\mathrm{L}^{-1} ; \mathbf{( H , I )}$ growth of select transgenic lines in selection medium; $(\mathbf{J}, \mathbf{K})$ stringent screeing of transgenic lines in selection medium (kanamycin $50 \mathrm{mg} \mathrm{L}^{-1}$ ); (L) well rooted putative mulberry transgenics with and without activated charcoal; (M) 2 month old mulberry transgenic plant showing deep green, shiny appearance compared to wild type. 

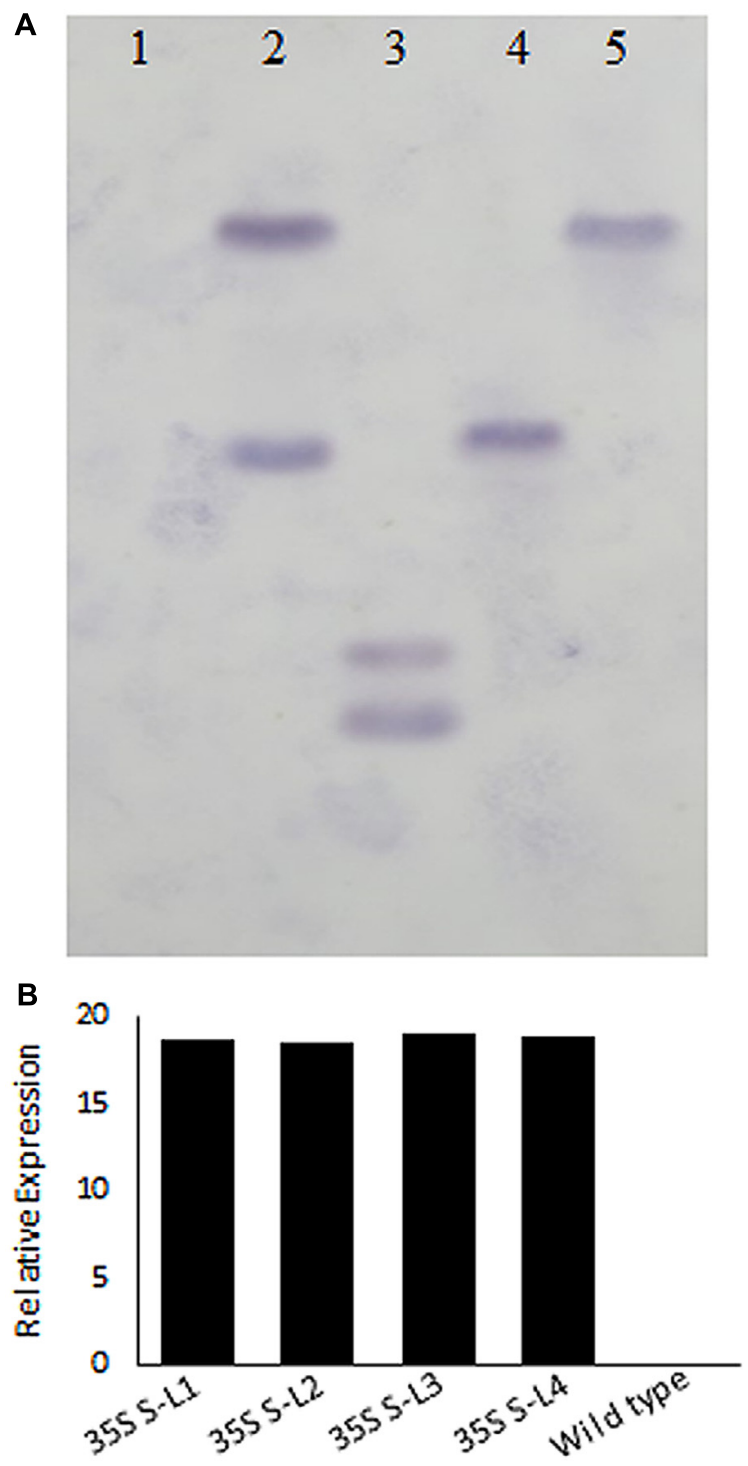

FIGURE 2 | Molecular characterization of transgenic and wild type mulberry plants. (A) Southern blot analysis using genomic DNA of transgenic and wild type plants. $15 \mu \mathrm{g}$ genomic DNA each from putative transgenic and wild type (untransformed) plants was digested with HindIII and probed with labeled Npt/l PCR product. Lane 1 is wild type (untransformed plant), Lanes 2-5 are different mulberry transgenic lines. (B) Relative expression of AtSHN1 gene in transgenic and wild type mulberry plants. 35S S-L1, L2, L3, and L4 are different transgenic lines.

transfer line temperature $300^{\circ} \mathrm{C}$, EI-mode was $70 \mathrm{eV}$, with the full scan-range 50-450 amu.

\section{Leaf Surface Hydrophobicity}

Contact angle, a measure of surface hydrophobicity, was measured by the contact angle goniometer method (Yuan and Lee, 2013). The measurements were made using demineralized deionized water droplets. Leaf disks were collected and placed on the measuring platform with double sided tape as adhesive. A known volume $(15 \mu \mathrm{l})$ of droplet was pointed

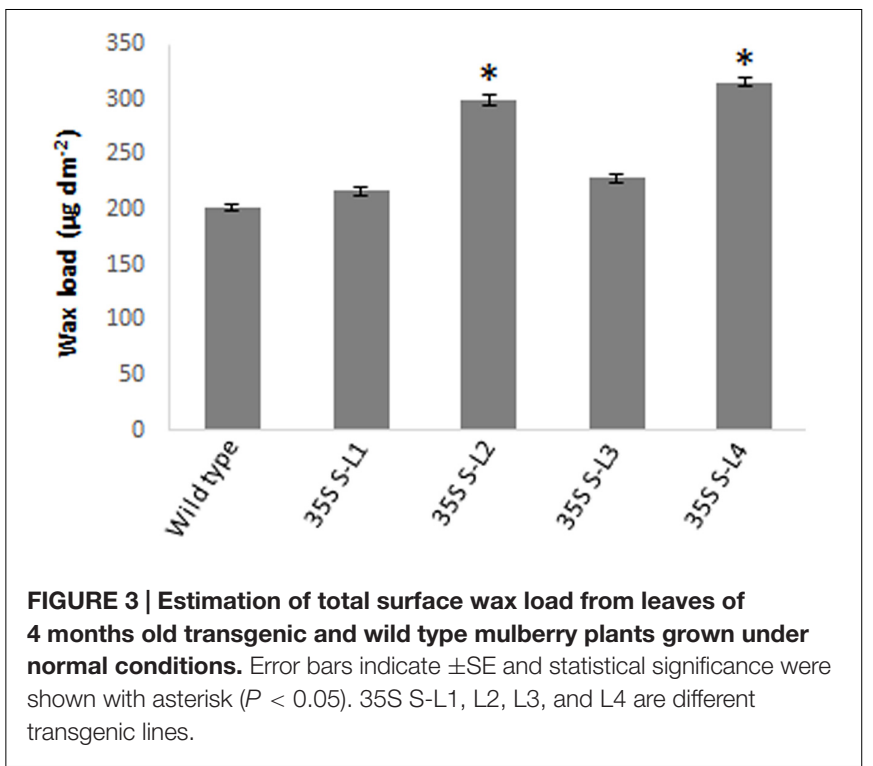

vertically down onto the sample surface and the contact angle was captured with a high resolution camera (Olympus B061, Japan) having a protractor mounted in the eye-piece. Diameter of the drop formed on the leaf is measured using a vertical stereoscope microscope, employing the stage and ocular micrometer. The diameter of water drop on the leaf is measured in two ways viz., north-south and east-west using the ocular micrometer and then expressed in millimeter $(\mathrm{mm})$. All measurements were made under laboratory conditions at temperature $25 \pm 1^{\circ} \mathrm{C}$ and relative humidity $(\mathrm{RH})$ of $50 \pm 5 \%$.

\section{Chlorophyll Leaching Assay}

For chlorophyll leaching assay, mature leaves were collected and rinsed with tap water, weighed, and put in tubes containing $20 \mathrm{~mL}$ of ethanol $(80 \%, \mathrm{v} / \mathrm{v})$ at room temperature (gently agitating in the dark). The amount of chlorophyll extracted into the solution was estimated every $30 \mathrm{~min}$ upto $5 \mathrm{~h}$ after recording the absorbance at wavelengths 663 and $645 \mathrm{~nm}$ using a spectrophotometer (SPECTRA max PLUS 384, Molecular devices; Hiscox and Israelstam, 1979).

\section{Moisture Retention Capacity (MRC)}

Leaves were harvested early in the morning and fresh weight recorded immediately. Leaf weight was recorded using an electronic balance with precision of $0.1 \mathrm{mg}$ (Sartorius, Gottingen, Germany) at hourly intervals up to $5 \mathrm{~h}$ (Mamrutha et al., 2010). The experiments were conducted at constant temperature $\left(30 \pm 0.5^{\circ} \mathrm{C}\right)$ and $\mathrm{RH}(55-60 \%)$ under a light intensity of $500-550 \mathrm{mmol} \mathrm{m}^{-2} \mathrm{~s}^{-1}$. At end of the experiment, leaves were dried to a constant weight in a hot air oven at $80^{\circ} \mathrm{C}$ for $24 \mathrm{~h}$. The MRC was estimated using the formula:

$$
\operatorname{MRC}(\%)=\left\{\left(\mathrm{FW}_{1}-\mathrm{DW}\right) /\left(\mathrm{FW}_{0}-\mathrm{DW}\right)\right\} \times 100
$$



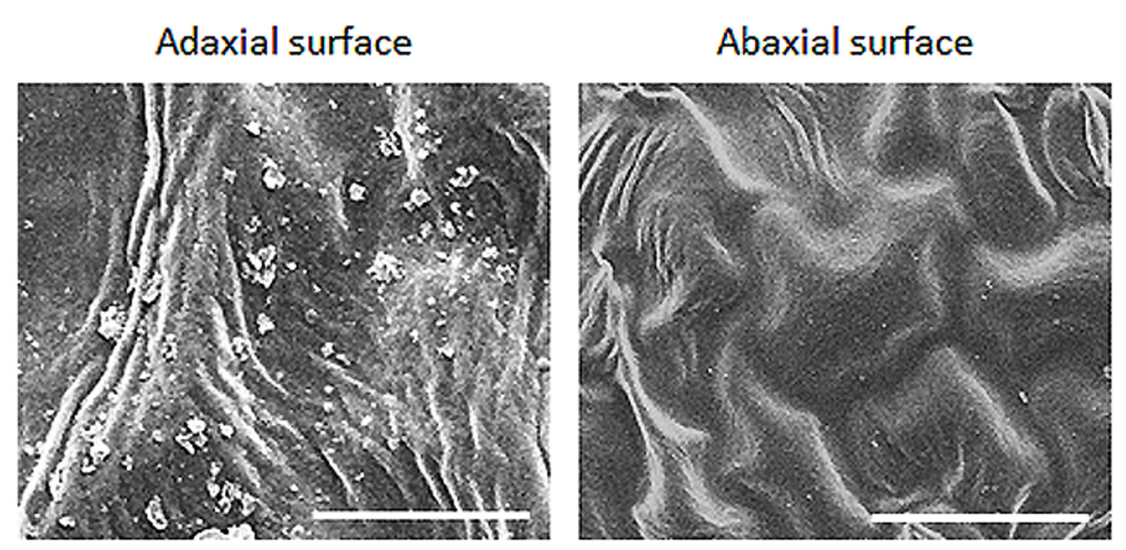

\section{Wild type}
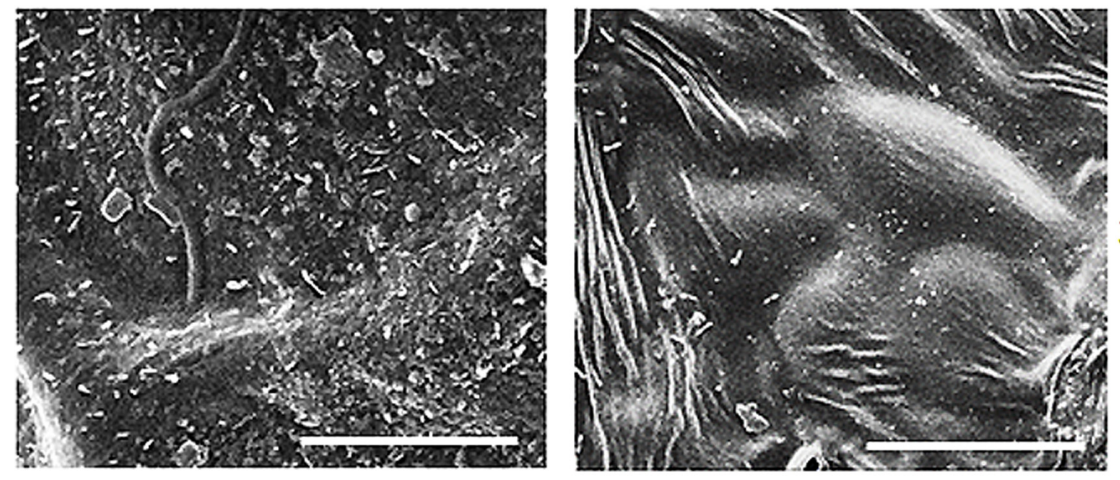

$35 \mathrm{~S} \mathrm{~S}-\mathrm{L} 2$
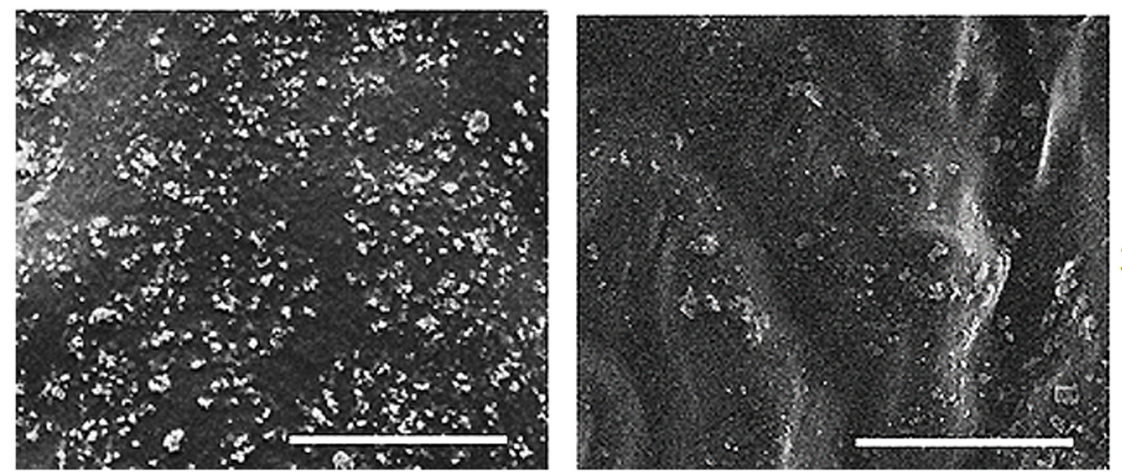

$35 S$ S - L4

FIGURE 4 | Analyses of wax crystals morphology in adaxial and abaxial sides of mulberry transgenics and wild type plants using scanning electron microscopy (SEM). The scale is $10 \mu \mathrm{m}$ with images taken at $5,000 \times$ magnification.

where, $\mathrm{FW}_{\mathrm{o}}$ is the fresh weight ( $\mathrm{g}$ ) immediately after harvest, $\mathrm{FW}_{1}$ is the weight $(\mathrm{g})$ at a particular hour after harvest and DW is the oven dry weight $(\mathrm{g})$.

\section{Soluble Protein Content}

The content of soluble protein was estimated from the leaf samples at different time points post-harvest following the method of Bradford (1976) and expressed as $\mathrm{mg} \mathrm{g}^{-1}$ fresh weight. The leaf sample of $0.1 \mathrm{~g}$ was macerated in $10 \mathrm{~mL}$ of phosphate buffer (0.1 M, pH 7.0) using a pestle and mortar. The color intensity in the protein extract after the reaction with reagent was recorded at wavelength $595 \mathrm{~nm}$ using a spectrophotometer (SPECTRA max PLUS 384, Molecular devices). Bovine serum albumin (BSA) was used as standard.

\section{Silkworm Bioassay}

Hybrid (PM $\times$ CSR2) bivoltine 5th larval instar worms of B. mori L. were procured from the College of Sericulture, University of Agricultural Sciences, Chintamani, Karnataka. Silkworms were reared on the fresh tender leaves of the AtSHN1 transgenic mulberry lines and wild type leaves at $24-28^{\circ} \mathrm{C}$ under a 16/8-h (light/dark) photoperiod under controlled environment conditions according to the protocol of Kawakami and Yanagawa (2003). Seventy larvae's were used for each treatment, fed thrice a day (at 8.00 AM, 2.00 and 8.00 PM). The molting larvae were mounted on bamboo mountage at the rate of 50 worms per square feet per treatment and cocoons were harvested after 5 days. The spacing of larvae and other rearing requirements were practiced as recommended by Sekharappa et al. (1991). Increase 
in weight of 5 th instar larvae was recorded from day 1 of rearing (gm). After complete mounting cocoon weight, shell weight and pupae weight were recorded (gm) and the effective rate of rearing (ERR) was calculated in percentage (\%) using the formula:

$$
\operatorname{ERR}(\%)=(\mathrm{Na} / \mathrm{Nb}) \times 100
$$

where, $\mathrm{Na}$ is number of cocoons obtained and $\mathrm{Nb}$ is number of worms brushed.

\section{Statistical Analysis}

All the experiments were conducted in three biological replicates unless otherwise mentioned and SE was computed in each case. For the estimation of statistical significance, Student's $t$-test was performed. The data points representing statistically significant differences between wild type and transgenic lines have been indicated.

\section{RESULTS}

\section{Agrobacterium Mediated Transformation and Generation of Transgenic Plants}

Full length of AtSHN1 (1135 bp) amplified from A. thaliana genome confirmed by sequencing (data not shown) was used for the construction of overexpression vector (Figure 1A). To generate transgenic mulberry through in vitro transformation approach, explants were pre-cultured on MS medium containing TDZ (0.1 $\mathrm{mg} \mathrm{L}^{-1}$ ) for 5 days (Figures 1B,F) and infected with Agrobacterium carrying the recombinant plasmid. Since bacterial cell density, infection time and co-cultivation duration are the important factors for transformation experiments, experimental conditions were standardized initially. Three days of co-cultivation in dark was found to be essential for infection without any negative effects on explants. Culturing the explants in a selection medium containing $\operatorname{TDZ}\left(0.1 \mathrm{mg} \mathrm{L}^{-1}\right)$, cefotaxime (200 $\left.\mathrm{mg} \mathrm{L}^{-1}\right)$, and kanamycin $\left(50 \mathrm{mg} \mathrm{L}^{-1}\right)$ for 45 days with a subculture at every 15 days interval yielded satisfactory results. Initially, 30 days post inoculation, nodules-like structures were noticed in the midrib region and basal cut ends. These structures later turned into shoot buds and subsequently regenerated into shoots (Figures 1C-E,G-I). Healthy shoots of 5-7 cm length (4-5 leaf stage) were separated (Figures 1J,K) and transferred to rooting media containing full or half strength MS and IBA (0.5 and $\left.1.0 \mathrm{mg} \mathrm{L}^{-1}\right)$ with or without activated charcoal $(1.0 \%$, w/v) (Figure 1L). Well rooted plantlets showed 80-90\% survival. The putative transgenic plants showed deep green and shiny phenotype compared to wild type plants under normal growth conditions (Figure 1M).

\section{Molecular Characterization of Transgenic Plants}

Polymerase chain reaction analysis carried out using nptII and AtSHN1 specific primers confirmed the integration of T-DNA into the mulberry genome (Supplementary Figures 1A,B). PCR with AtSHN1 specific forward primer and Nos Terminator reverse primer yielded 1460 bp product which was eluted and sequenced (Supplementary Figures 1C,D). Southern hybridization carried out using probe specific to nptII (Figure 2A) showed the integration of T-DNA in the genome of transgenic lines (Figure 2A). Expression of AtSHN1 in transgenic lines assayed by RT-PCR indicated expression of transgene (Figure 2B).

\section{Epicuticular Wax Load and Scanning Electron Microscopy (SEM)}

Significant difference $(P<0.05)$ was observed in total wax load between transgenic and wild type plants. Total wax load was 0.75 to 1.2 -fold higher in AtSHN1 overexpression lines compared to wild type plants (Figure 3). SEM analysis showed difference in epicuticular wax crystal morphology between transgenic and wild type mulberry plants. Expression of AtSHN1 changed the pattern of epicuticular wax crystals on the adaxial and abaxial leaf surfaces. Compared to adaxial leaf surface, there were fewer wax crystals observed in abaxial surface of mulberry transgenic plants (Figure 4).

\section{Analysis of Epicuticular Wax Components}

Wax components in leaf samples were analyzed by GC-MS in selected transgenic mulberry lines (S-L2 and S-L4). There were significant differences $(P<0.05)$ in wax components between the wild type and transgenic mulberry plants. Higher alkanes were 2.2-fold more (72 and 71\%) in mulberry AtSHN1 overexpressors compared to wild type plants $(32 \%)$ whereas alcohols and esters were significantly reduced with 3.2 and 2.5 -fold reduction in alcohol (3.9 and 4.4\%) and ester levels (21 and 21.9\%) compared to wild type plants (14 and 51\%) respectively (Figure 5).

\section{Leaf Surface Properties and Cuticular Permeability}

A significant difference $(P<0.05)$ in extent of hydrophobicity was observed between transgenic and wild type mulberry leaf surfaces (Table 1). Lower contact angle of water droplets

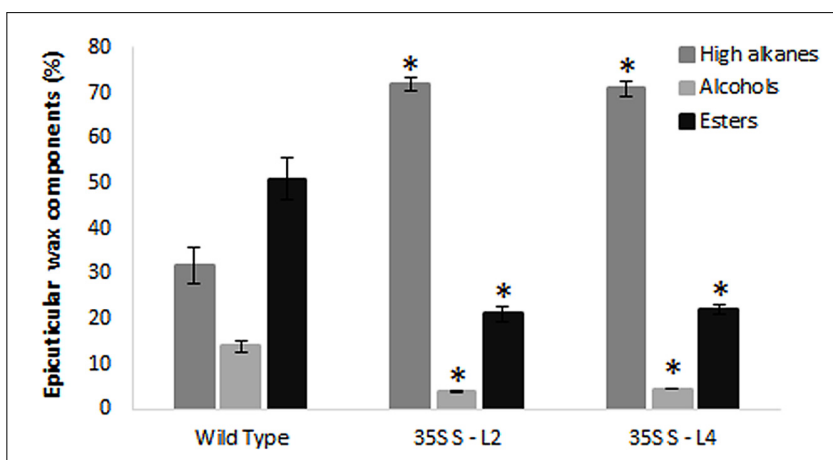

FIGURE 5 | Analyses of leaf wax components in transgenics and wild type mulberry plants. Wax constituents of higher alkanes, alcohols, and esters in leaves are expressed as percent of total wax. The results show averages of three replicates and statistical significance were shown with asterisk $(P<0.05)$ and error bars indicate mean \pm SE. 
TABLE 1 | Contact angle and droplet diameter of mulberry transgenics and wild type plants.

\begin{tabular}{lccc}
\hline SI. No. & Name & Contact angle $\left(^{\circ}\right)$ & Droplet diameter $(\mathbf{m m})$ \\
\hline$(1)$ & Wild type & $56 \pm 1.20$ & $4.61 \pm 0.46$ \\
$(2)$ & 35S S-L1 & $79 \pm 1.60^{*}$ & $3.70 \pm 0.29$ \\
$(3)$ & $35 S$ S-L2 & $72 \pm 1.13^{*}$ & $3.84 \pm 2.19$ \\
$(4)$ & $35 S$ S-L3 & $74 \pm 0.91^{*}$ & $3.72 \pm 0.92$ \\
$(5)$ & 35S S-L4 & $81 \pm 0.75^{*}$ & $3.17 \pm 0.98^{*}$ \\
\hline
\end{tabular}

The values show average of five replications and mean $\pm S E$. Asterisk indicates statistical significance $(P<0.05)$.

in wild type $\left(55^{\circ}\right)$, than transgenic lines $\left(72-81^{\circ}\right)$ indicated changes in leaf surface properties (Table $\mathbf{1}$ and Figures 6A,B). Similarly, we noticed differences in droplet diameter between wild type and transgenic lines (Table 1 and Figures 6C,D). Chlorophyll leaching assay was carried out to test the cuticular membrane permeability in fully mature leaves. Significantly higher $(P<0.05)$ quantities of chlorophyll could be extracted from wild type compared to transgenic lines suggesting higher cuticular resistance for chlorophyll leaching in transgenic lines (Figure 7).

\section{Moisture Retention Capacity and Soluble Protein Content}

Transgenic mulberry plants expressing AtSHN1 showed significant reduction in post-harvest water loss through cuticle compared to wild type plants. Transgenic lines maintained higher leaf moisture content (48-54\%) compared to wild type (37\%), even after $5 \mathrm{~h}$ of harvest (Figure 8). To compare the beneficial effect of the higher MRC in transgenic plants, we quantified the total buffer soluble protein in the harvested leaves. Three AtSHN1 overexpression lines (35S S-L2, L3, and L4) showed delay in protein degradation as indicated by higher protein content at 1,3 , and $5 \mathrm{~h}$ post-harvest compared to wild type plants (Figure 9), which might be due to slow protein degradation post-harvest.

\section{Silkworm Bioassay}

A silkworm bioassay was conducted to study the effect of the transgene protein on B. mori larvae, feeding and rearing. Young tender leaves from wild type and transgenic plants were fed to the 5 th instar larvae thrice a day (Figure 10A). An increase in larvae's weight was observed daily, but there was no significant difference noticed between the larvae fed with wild type and transgenic plant leaves (Supplementary Table 2A). There was no significant difference in cocoon weight between wild type and transgenic treatments (Figure 10B and Supplementary Table 2B). There was an increase in shell, pupal weight and ERR of silkworms fed with transgenic lines compared to wild type (Supplementary Table 2B).

\section{DISCUSSION}

Leaf surface properties, wax content and wax crystal morphology influence post-harvest water loss in mulberry (Mamrutha et al., 2010). Plant cuticle plays an important role in limiting water loss as demonstrated in many different studies (Schreiber and Riederer, 1996; Jenks and Ashworth, 1999; Riederer and Schreiber, 2001; Jenks et al., 2002). Targeted manipulation of cuticular wax biosynthetic pathway can be a viable option to increase surface wax in plants. Many TFs associated with wax production have been identified and their relevance demonstrated in plants (Broun et al., 2004; Karaba et al., 2007a,b; Seo et al., 2011; Lam et al., 2012; Yeats and Rose, 2013). Many earlier studies have shown that AtSHN1 overexpressing plants exhibit altered epidermal properties resulting in tolerance to dehydration stress (Aharoni et al., 2004; Kannangara et al., 2007). In an attempt to reduce the post-harvest water loss by altering the leaf surface wax load in mulberry, we expressed AtSHN1 gene cloned from Arabidopsis in mulberry under a constitutive CaMV35S promoter.

Over 1.2-fold increase in total wax content in transgenic lines suggests that AtSHN1 expression activated wax biosynthesis and secretion pathways in mulberry. A strong positive relationship between surface wax load and MRC of harvested leaves of mulberry as reported by Mamrutha et al. (2010) suggest that water loss can be minimized by altering surface waxes. The permeability barrier properties of cuticle are mainly determined by the aliphatic constituents of the cuticular waxes (Vogg et al., 2004). The increase in amount of higher alkanes and decline in alcohol and ester levels in AtSHN1 overexpressors, accompanied by an increase in cuticular resistance seen in the mulberry transgenic plants signifies the importance of alkanes in determining MRC. A disproportionate build-up of higher alkanes, in contrast with the reduction in alcohol and ester levels in mulberry SHN1 overexpressors, suggests a preferential increase in flux through the decarbonylation pathway, than the acyl reduction pathway. By contrast to our study, the shn mutants in Arabidopsis showed a sharp increase in alkanes, primary and secondary alcohols, alkyl esters, ketones, and aldehydes resulting from both the decarbonylation and acyl reduction pathways (Aharoni et al., 2004). There are evidences to indicate that different wax biosynthesis genes or their homologs from other distant plant species contribute for the variations in wax compositions (Chen et al., 2003; Sturaro et al., 2005; Zhang et al., 2005; Wang et al., 2012). For example, SHN1/WIN1 in Arabidopsis increases cuticular wax load by mainly altering alkane content (Aharoni et al., 2004; Broun et al., 2004), where as in Medicago primary alcohol, a predominant wax component, is probably regulated by WXP1 (Zhang et al., 2005). It has also been reported that alkanes are predominantly present in the mature leaves of Arabidopsis (Suh et al., 2005; Seo et al., 2011), maize (Blaker and Greyson, 1988), tree tobacco (Cameron et al., 2006), tomato (Leide et al., 2007). In the present study, an increase in alkane concentration was observed in AtSHN1 transgenic plants and the shift in wax composition may lead to changes in overall surface wax crystallinity in mulberry leaves.

Since droplet contact angle and droplet diameter studies help in understanding the properties of leaf surface, we measured this parameter. Leaf is considered hydrophilic when it forms a contact angle less than $90^{\circ}$ and nearer or greater than $90^{\circ}$ considered as hydrophobic (Bhushan, 2003; Bhushan et al., 2004). Transgenic 

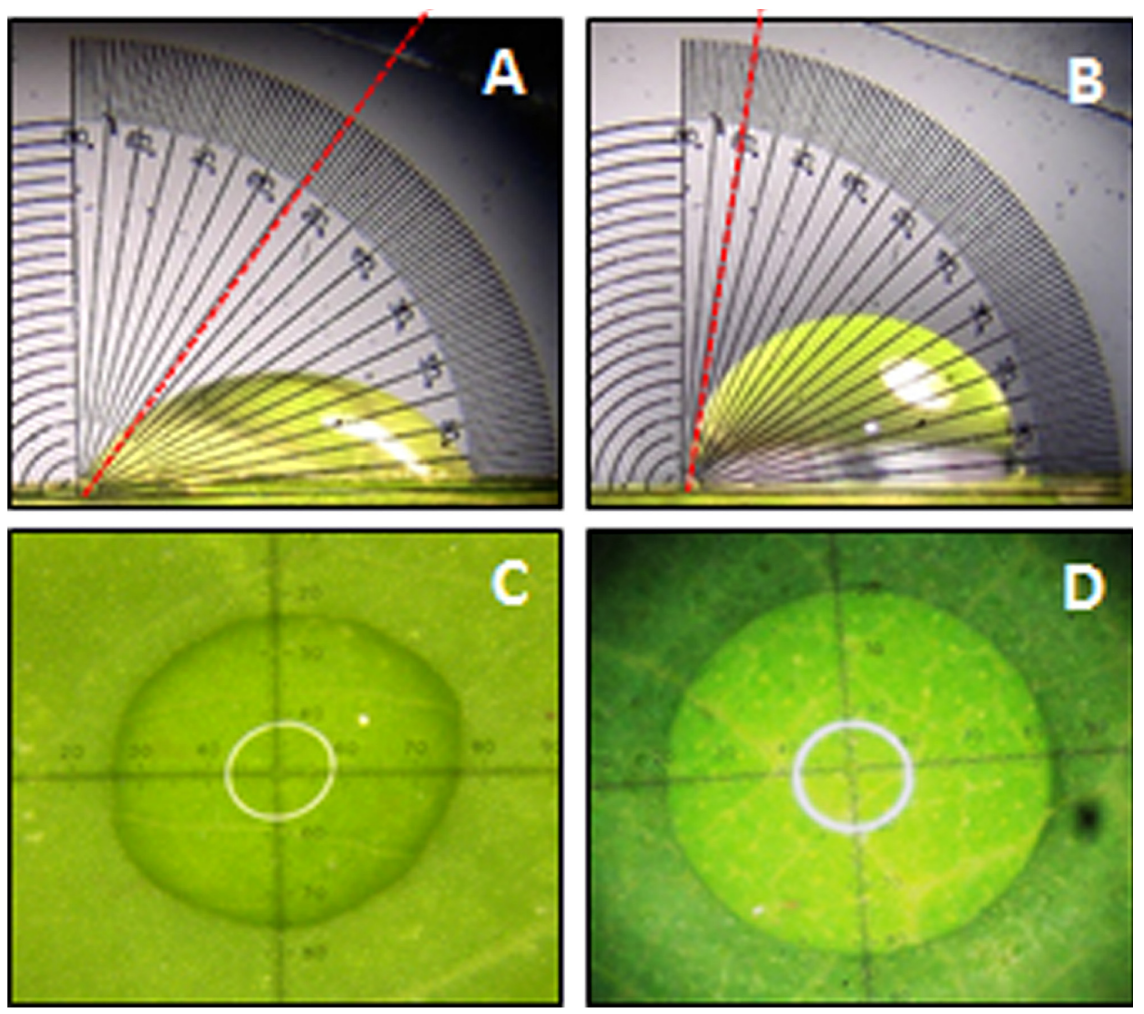

FIGURE 6 | Measurement of water drop characteristics on leaves of mulberry transgenics and wild type plants. (A,B) Contact angle of wild type and AtSHN1 overexpressors, red doted line shows the contact angle of droplets; (C,D) droplet diameter of wild type and AtSHN1 overexpressors.

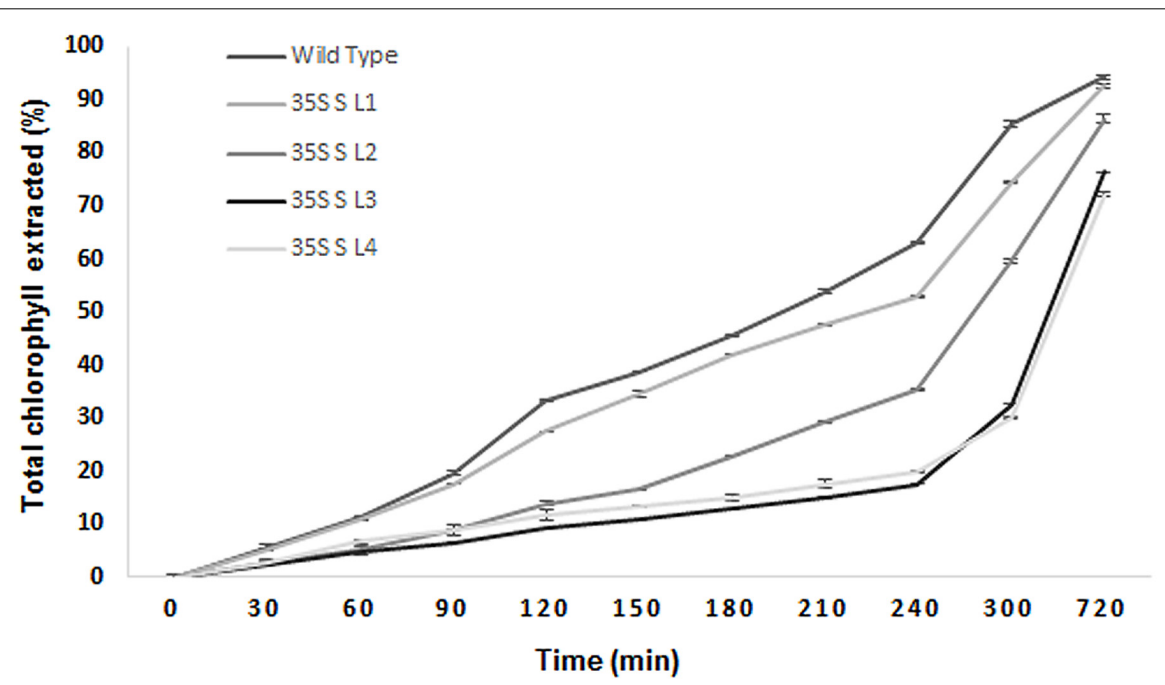

FIGURE 7 | Chlorophyll leaching assay using leaves collected from wild type and transgenic mulberry plants at different time points. The results show averages of three replicates, 35S S-L1, L2, L3, and L4 are different transgenic lines.

lines showed more contact angle and less droplet diameter (spreading) compared to wild type plants. Rice mutants for Wax crystal-sparse leaf2 ( $w s l 2$ ), displayed more droplet spreading, unlike water droplets forming beads in wild type (Mao et al., 2012). Cuticle permeability is strongly influenced by the quantity and composition of cuticular wax present. Chlorophyll efflux/leaching assay showed significant reduction in chlorophyll extracted from mulberry AtSHN1 overexpressors compared to wild type plants, consistent with observations of reduced post-harvest water loss. Our results were contradictory with 


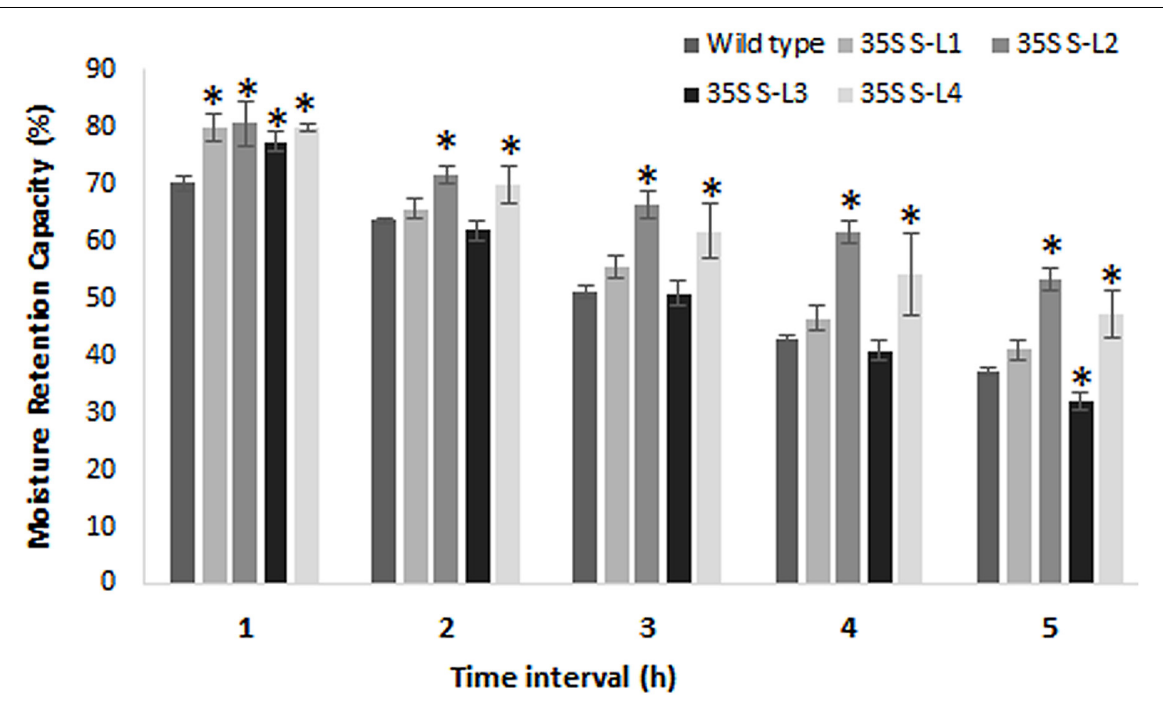

FIGURE $\mathbf{8}$ | Estimation of moisture retention capacity of leaves of $\mathbf{4}$ months old transgenic and wild type mulberry plants. Error bars indicate mean \pm SE and statistical significance of differences between wild type and transgenic plants are indicated with asterisk $(P<0.05)$. 35S S-L1, L2, L3, and L4 are different transgenic lines.

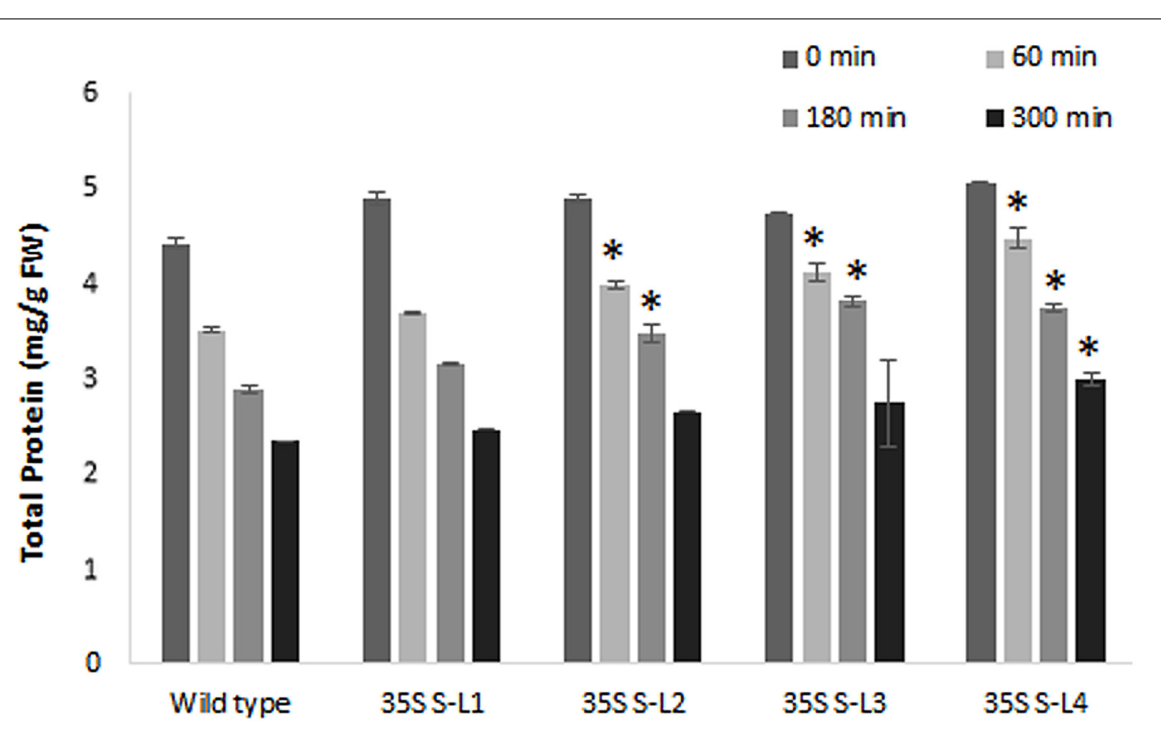

FIGURE 9 | Estimation of total soluble protein content from detached leaves of $\mathbf{4}$ months old transgenic and wild type mulberry plants at different time intervals. Error bars indicate mean \pm SE and statistical significance was shown with asterisk $(P<0.05)$. 35S S-L1, L2, L3, and L4 are different transgenic lines.

the results of Aharoni et al. (2004) in Arabidopsis, and is in agreement with the findings of Wang et al. (2012), who demonstrated that the expression of OsWR1, a homolog of AtWIN1/SHN1, reduces chlorophyll leaching and water loss from dissected leaves of rice while RNA interference (RNAi) of OsWR1 increases chlorophyll leaching and water loss. In our study, AtSHN1 expression resulted in significant improvement in moisture retention ability in comparison to wild type plants even after $5 \mathrm{~h}$ post-harvest. Higher MRC of harvested leaves may contribute for the maintenance of better leaf quality for a longer period, which was evident in our study as there was higher buffer soluble protein content in leaves at different time points post-harvest in transgenic lines when compared to wild type plants.

To examine the effect of AtSHN1 overexpression on silkworm growth and cocoon parameters, we carried out silkworm bioassay. Our silkworm bioassay led to the conclusion that over production of SHN1 protein and associated phenotypic changes, (increase in epicuticular wax content) has no deleterious effect on the growth and feeding behavior of silkworm larvae. The cocoon produced from the silkworms fed with transgenic mulberry leaves did not show any difference in color or texture (Figure 10B). Similar results were also reported by Lal et al. (2008) and Das et al. (2011) in silkworm rearing studies using the transgenic 


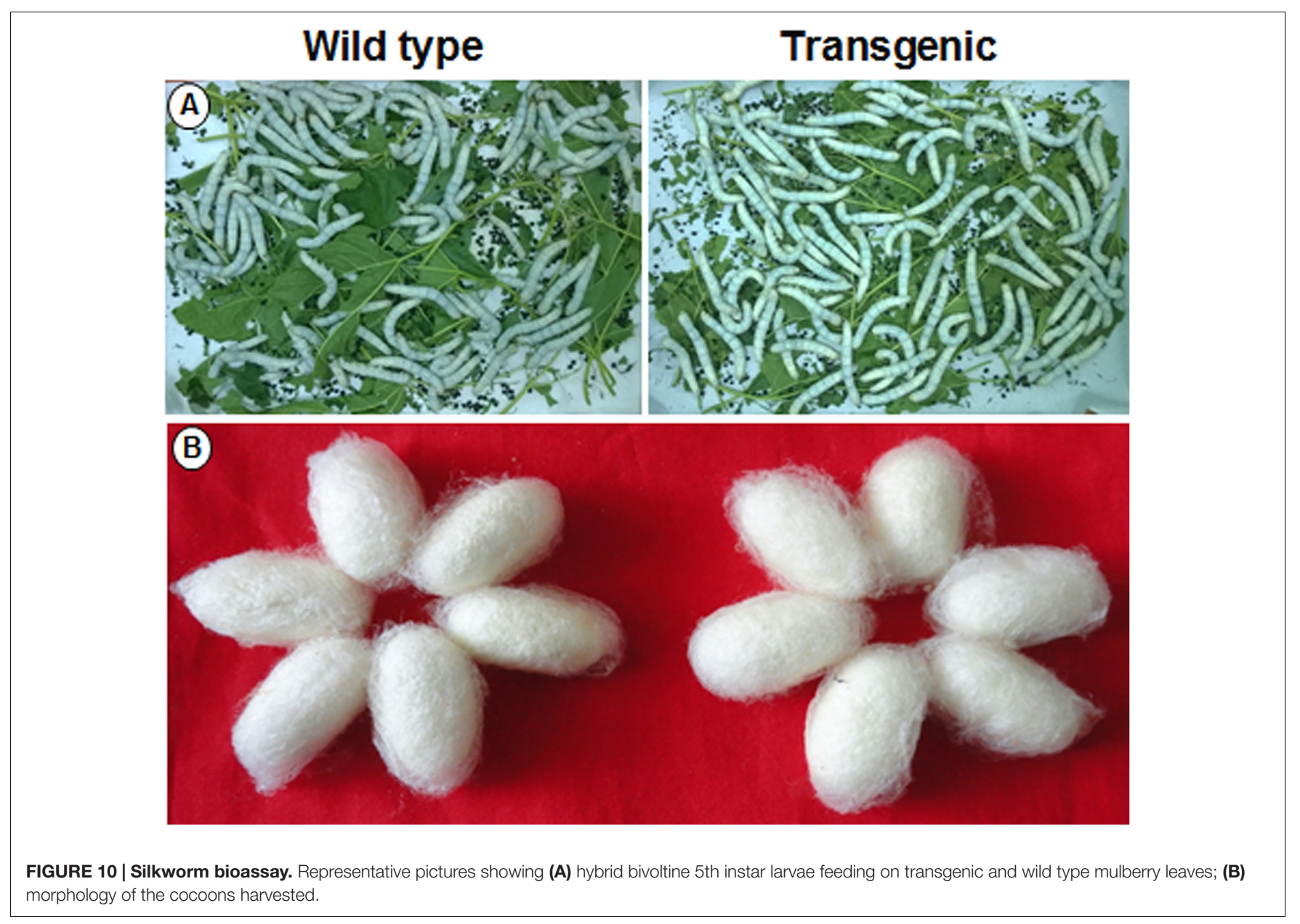

mulberry leaves expressing tobacco osmotin and barley HVA1 genes. Since commercial sericulture involves indoor rearing of silkworms using harvested mulberry leaves, any improvement in MRC, as demonstrated in this study can contribute for leaf quality and hence cocoon yield. In summary, the study demonstrated that overexpression of AtSHN1 gene in mulberry can enhance the total wax load, alter leaf surface properties and help in delaying post-harvest water loss. The study also demonstrated that overexpression of upstream regulatory gene/s associated with specific trait/s can be viable approach for targeted crop improvement in perennial tree crops such as mulberry.

\section{DATA ARCHIVING STATEMENT}

Gene sequence used in this study was reported earlier in "The Arabidopsis Information Resource (TAIR) database" and the accession number of the gene is given in the section "Materials and Methods."

\section{AUTHOR CONTRIBUTIONS}

Conceived and designed the experiments: KN and RS. Performed the experiments: RS, KS, NP, and DG. Analyzed the data: RS,
KS, and KN. Contributed reagents/materials/analysis tools: KN. Wrote the paper: RS, KN, DG, and MS.

\section{FUNDING}

This project is financially supported by the Department of Biotechnology (DBT), Government of India (GOI), New Delhi to $\mathrm{KN}$.

\section{ACKNOWLEDGMENTS}

We wish to thank Dr. Jagadeesh and Mr. Anuj Bisht, Indian Institute of Science (IISc), Bengaluru, Karnataka for the support extended during the SEM analysis and Dr. Jalendra Kumar H. G. and Dr. Vikram S. R., UAS, Bengaluru, Karnataka for their help in contact angle and droplet diameter measurements.

\section{SUPPLEMENTARY MATERIAL}

The Supplementary Material for this article can be found online at: http://journal.frontiersin.org/article/10.3389/fpls.2017.00418/ full\#supplementary-material 


\section{REFERENCES}

Aharoni, A., Shital, D., Reinhard, J., Eveline, T., Gertv, A., and Andy, P. (2004). The Shine clade of AP2 domain transcription factors activates wax biosynthesis, alters cuticle properties and confers drought tolerance when overexpressed in Arabidopsis. Plant Cell 16, 2463-2480. doi: 10.1105/tpc.104.022897

Bhatnagar, S., and Khurana, P. (2003). Agrobacterium tumefaciens mediated transformation of Indian mulberry Morus indica cv. K2 a time phased screening strategy. Plant Cell Rep. 21, 669-675.

Bhushan, B. (2003). Adhesion and stiction: mechanisms, measurement techniques and methods for reduction. J. Vac. Sci. Technol. B. 21, 2262-2296. doi: 10.1116/ 1.1627336

Bhushan, B., Liu, H., and Hsu, S. M. (2004). Adhesion and friction studies of silicon and hydrophobic and low friction film and investigation of scale effects. ASME J. Tribol. 126, 583. doi: 10.1115/1.1739407

Blaker, T. W., and Greyson, R. I. (1988). Developmental variation of leaf surface wax of maize, Zea mays. Can. J. Bot. 66, 839-846. doi: 10.1139/b88-122

Borisjuk, N., Hrmova, M., and Lopato, S. (2014). Transcriptional regulation of cuticle biosynthesis. Biotechnol. Adv. 32, 526-540. doi: 10.1016/j.biotechadv. 2014.01.005

Bradford, M. M. (1976). A rapid and sensitive for the quantitation of microgram quantities of protein utilizing the principle of protein-dye binding. Anal. Biochem. 72, 248-254. doi: 10.1016/0003-2697(76)90527-3

Broun, P., Poindexter, P., Osborne, E., Jiang, C. Z., and Riechmann, J. L. (2004). WIN1 a transcriptional activator of epidermal wax accumulation in Arabidopsis. Proc. Natl. Acad. Sci. U.S.A. 101, 4706-4711. doi: 10.1073/pnas.0305574101

Cameron, K. D., Teece, M. A., and Smart, L. B. (2006). Increased accumulation of cuticular wax and expression of lipid transfer protein in response to periodic drying events in leaves of tree tobacco. Plant Physiol. 140, 176-183. doi: 10.1104/ pp.105.069724

Central Silk Board (2014-2015). Annual Report. Bengaluru: Central Silk Board. doi: $10.1105 /$ tpc.010926

Chen, X., Goodwin, S. M., Boroff, V. L., Liu, X., and Jenks, M. A. (2003). Cloning and characterization of the WAX2 gene of Arabidopsis involved in cuticle membrane and wax production. Plant Cell 15, 1170-1185. doi: 10.1105/tpc. 010926

Chuong, S. D. X., Franceschi, V. R., and Edwards, G. E. (2006). The cytoskeleton maintains organelle partitioning required for single-cell $\mathrm{C} 4$ photosynthesis in Chenopodiaceae species. Plant Cell 18, 2207-2223. doi: 10.1105/tpc.105. 036186

Das, M., Chauhan, H., Chhibbar, A., Haq, M. R., and Khurana, P. (2011). High efficiency transformation and selective tolerance against biotic and abiotic stress in mulberry, Morus indica cv. K2, by constitutive and inducible expression of tobacco osmotin. Transgenic Res. 20, 231-246. doi: 10.1007/s11248-0109405-6

Ebercon, A., Blum, A., and Jordan, W. R. (1977). A rapid colorimetric method for epicuticular wax content of sorghum leaves. Crop Sci. 17, 179-180. doi: 10.2135/cropsci1977.0011183X001700010047x

Gutierrez, A., del Rio, T. C., Gonzalez-Vila, F. J., and Martin, F. (1998). Analysis of lipophilic extractives from wood and pitch deposits by solid-phase extraction and gas chromatography. J. Chromatogr. A 823, 449-455. doi: 10.1007/s11103009-9483-0

Hiscox, J. D., and Israelstam, G. F. (1979). A method for the extraction of chlorophyll from leaf tissues without maceration. Can. J. Bot. 57, 1332-1334. doi: 10.1139/b79-163

Javelle, M., Vernoud, V., Depege-Fargeix, N., Arnould, C., Oursel, D., Domergue, F., et al. (2010). Overexpression of the epidermis-specific homeo domain 31 leucine zipper IV transcription factor Outer Cell Layer1 in maize identifies target genes involved in lipid metabolism and cuticle biosynthesis. Plant Physiol. 154, 273-286. doi: 10.1104/pp.109.150540

Jenks, M. A., and Ashworth, E. N. (1999). Plant epicuticular waxes function, production and genetics. Hortic. Rev. 23, 1-68.

Jenks, M. A., Eigenbrode, S. D., and Lemeiux, B. (2002). "Cuticular waxes of Arabidopsis," in The Arabidopsis Book, eds C. R. Somerville and E. M. Meyerowitz (Rockville MD: American Society of Plant Biologists).

Jenks, M. A., Rashotte, A. M., Tuttle, H. A., and Feldmann, K. A. (1996). Mutants in Arabidopsis thaliana altered in epicuticular wax and leaf morphology. Plant Physiol. 110, 377-385. doi: 10.1104/pp.110.2.377
Kannangara, R., Branigan, C., Liu, Y., Penfield, T., Rao, V., Mouille, G., et al. (2007). The transcription factor WIN1/SHN1 regulates cutin biosynthesis in Arabidopsis thaliana. Plant Cell 19, 1278-1294. doi: 10.1105/tpc.106.047076

Karaba, A., Kurniawan, R., Trijatmiko, Karaba, N. N., Udayakumar, M., and Pereira, A. (2007a). "Chapter 5-Improvement of water use efficiency and drought resistance in rice by expression of Arabidopsis genes involved in wax biosynthesis," in Improvement of Water Use Efficiency in Rice and Tomato Using Arabidopsis Wax Biosynthetic Genes and Transcription Factors, ed. A. Karaba (Wageningen: Plant Research International Wageningen University and Research Center the Netherlands), 95-116.

Karaba, A., Karaba, N. N., Udayakumar, M., Buschhaus, C., Alikpala, E., Jetter, R., et al. (2007b). "Chapter 4-Improvement of water use efficiency in tomato by alteration of epidermal properties using Arabidopsis wax biosynthesis genes," in Improvement of Water Use Efficiency in Rice and Tomato Using Arabidopsis Wax Biosynthetic Genes and Transcription Factors, ed. A. Karaba (Wageningen: Plant Research International Wageningen University and Research Center the Netherlands), 61-94.

Kawakami, K., and Yanagawa, H. (2003). Illustrated Working Process of New Bivoltine Silkworm Rearing Technology. New Delhi: JICA.

Kunst, L., Jetter, R., and Samuels, A. L. (2006). "Biosynthesis and transport of plant cuticular waxes," in Biology of the Plant Cuticle, eds M. Riederer and C. Müller (Oxford UK: Blackwell Publishing), 182-215. doi: 10.1002/9780470988718.ch5

Kunst, L., and Samuels, A. L. (2009). Plant cuticles shine advances in wax biosynthesis and export. Curr. Opin. Plant Biol. 12, 721-727. doi: 10.1016/j.pbi. 2009.09.009

Lal, S., Gulyani, V., and Khurana, P. (2008). Over expression of HVA1 gene from barley generates tolerance to salinity and water stress in transgenic mulberry (Morus indica). Transgenic Res. 17, 651-663. doi: 10.1007/s11248-007-9145-4

Lam, P., Zhao, L., McFarlane, H. E., Aiga, M., Lam, V., Hooker, T. S., et al. (2012). RDR1 and SGS3 components of RNA-mediated gene silencing are required for regulation of cuticular wax biosynthesis in developing stems of Arabidopsis. Plant Physiol. 159, 1385-1395. doi: 10.1104/pp.112.199646

Lee, S. B., Kim, H., Kim, R. J., and Suh, M. C. (2014). Overexpression of Arabidopsis MYB96 confers drought resistance in Camelina sativa via cuticular wax accumulation. Plant Cell Rep. 33, 1535-1546. doi: 10.1007/s00299-0141636- 1

Lee, S. B., and Suh, M. C. (2015a). Advances in the understanding of cuticular waxes in Arabidopsis thaliana and crop species. Plant Cell Rep. 34, 557-572. doi: 10.1007/s00299-015-1772-2

Lee, S. B., and Suh, M. C. (2015b). Cuticular wax biosynthesis is up-regulated by the MYB94 transcription factor in Arabidopsis. Plant Cell Physiol. 56, 48-60. doi: $10.1093 / \mathrm{pcp} / \mathrm{pcu} 142$

Leide, J., Hildebrandt, U., Reussing, K., Riederer, M., and Vogg, G. (2007). The developmental pattern of tomato fruit wax accumulation and its impact on cuticular transpiration barrier properties: effects of a deficiency in a b-ketoacylcoenzyme a synthase (LeCER6). Plant Physiol. 144, 1667-1679. doi: 10.1104/pp. 107.099481

Mamrutha, H. M., Mogili, T., JhansiLakshmi, K., Rama, N., Kosma, D., UdayaKumar, M., et al. (2010). Leaf cuticular wax amount and crystal morphology regulate post-harvest water loss in mulberry (Morus species). Plant Physiol. Biochem. 48, 690-696. doi: 10.1016/j.plaphy.2010.04.007

Mamrutha, H. M., Nataraja, K. N., Rama, N., Kosma, D. K., Mogili, T., JhansiLakshmi, K., et al. (2017). Leaf surface wax composition of genetically diverse mulberry (Morus sp.) genotypes and its close association with expression of genes involved in wax metabolism. Curr. Sci. 112, 759-766. doi: 10.18520/cs/ v112/i04/759-766

Mao, B. G., Cheng, Z. J., Lei, C. L., Xu, F. H., Gao, S. W., Ren, Y., et al. (2012). Wax crystal-sparse leaf 2 a rice homologue of WAX2/GL1 is involved in synthesis of leaf cuticular wax. Planta 235, 39-52. doi: 10.1007/s00425-0111481-1

Muhammad, A. L., Ye, G. N., Weeden, N. F., and Reisch, B. I. (1994). A simple and efficient method for DNA extraction from grapevine cultivars Vitis species and Ampelopsis. Plant Mol. Biol. Rep. 12, 6-13. doi: 10.1007/BF02668658

Murashige, T., and Skoog, F. (1962). A revised medium for rapid growth and bioassays with tobacco tissue cultures. Physiol. Plant. 15, 473-497. doi: 10.1111/ j.1399-3054.1962.tb08052.x

Oshima, Y., Shikata, M., Koyama, T., Ohtsubo, N., Mitsuda, N., and Ohme-Takagi, M. (2013). MIXTA-Like transcription factors and WAX 
INDUCER1/SHINE1 co-ordinately regulate cuticle development in Arabidopsis and Torenia fournieri. Plant Cell 25, 1609-1624. doi: 10.1105/tpc.113. 110783

Park, C. S., Go, Y. S., and Suh, M. C. (2016). Cuticular wax biosynthesis is positively regulated by WRINKLED4, an AP2/ERF-type transcription factor, in Arabidopsis stems. Plant J. 88, 257-270. doi: 10.1111/tpj. 13248

Rao, A. A. (2002). "Conservation status of mulberry genetic resources in India," in Proceedings of the Paper Contributed to Expert Consultation on Promotion of Global Exchange of Sericultural Germplasm Resources, Satellite session of XIXth ISC Congress, Bangkok, 21-25.

Riederer, M., and Schreiber, L. (2001). Protecting against water loss analysis of the barrier properties of plant cuticles. J. Exp. Bot. 52, 2023-2032. doi: 10.1093/ jexbot/52.363.2023

Sajeevan, R. S., Shivanna, M. B., and Nataraja, K. N. (2014). An efficient protocol for total RNA isolation from healthy and stressed tissues of mulberry (Morus sp.) and other species. Am. J. Plant. Sci. 2014, 2057-2065. doi: 10.4236/ajps.2014. 513221

Sambrook, J., Fritsch, E. F., and Maniatis, T. (1989). Molecular Cloning: A laboratory manual, 3rd Edn. Cold Spring Harbor, NY: Cold Spring Harbor Laboratory Press.

Samdur, M. Y., Manivel, P., Jain, V. K., Chikani, B. M., Gor, H. K., Desai, S., et al. (2003). Genotypic differences and water-deficit induced enhancement in epicuticular wax load in peanut. Crop Sci. 43, 1294-1299. doi: 10.2135/ cropsci2003.1294

Samuels, L., Kunst, L., and Jetter, R. (2008). Sealing plant surfaces cuticular wax formation by epidermal cells. Ann. Rev. Plant Biol. 59, 683-707. doi: 10.1146/ annurev.arplant.59.103006.093219

Schreiber, L., Kirsch, T., and Riederer, M. (1996). "Diffusion through cuticles: principles and models," in Plant Cuticles: an Integrated Functional Approach, ed. G. Kerstiens (Oxford: BIOS Scientific Publishers), 109-120.

Schreiber, L., and Riederer, M. (1996). Ecophysiology of cuticular transpiration: comparative investigation of cuticular water permeability of plant species from different habitats. Oecologia 107, 426-432. doi: 10.1007/BF003 33931

Sekharappa, B. M., Gururaj, G. S., and Muniraju, E. (1991). Shoot feeding technology for late age silkworm rearing. Indian Silk 30, 37-43.

Seo, P. J., Lee, S. B., Suh, M. C., Park, M. J., Go, Y. S., and Park, C. M. (2011). The MYB96 transcription factor regulates cuticular wax biosynthesis under drought conditions in Arabidopsis. Plant Cell 23, 1138-1152. doi: 10.1105/tpc. 111.083485

Sturaro, M., Hartings, H., Schmelzer, E., Velasco, R., Salamini, F., and Motto, M. (2005). Cloning and characterization of GLOSSY1, a maize gene involved in cuticle membrane and wax production. Plant Physiol. 138, 478-489. doi: $10.1104 /$ pp.104.058164

Suh, M. C., Samuels, A. L., Jetter, R., Kunst, L., Pollard, M., Ohlrogge, J., et al. (2005). Cuticular lipid composition, surface structure, and gene expression in Arabidopsis stem epidermis. Plant Physiol. 139, 1649-1665. doi: 10.1104/pp.105. 070805

Vogg, G., Fischer, S., Leide, J., Emmanuel, E., Jetter, R., Levy, A. A., et al. (2004). Tomato fruit cuticular waxes and their effects on transpiration barrier properties: functional characterization of a mutant deficient in a verylong-chain fatty acid $\beta$-ketoacyl-CoA synthase. J. Exp. Bot. 55, 1401-1410. doi: $10.1093 /$ jxb/erh149

Wang, Y., Wan, L., Zhang, L., Zhang, Z., Zhang, H., Quan, R., et al. (2012). An ethylene response factor OsWR1 responsive to drought stress transcriptionally activates wax synthesis related genes and increases wax production in rice. Plant Mol. Biol. 78, 275-288. doi: 10.1007/s11103-011-9861-2

Yeats, T. H., and Rose, J. K. C. (2013). The formation and function of plant cuticles. Plant Physiol. 163, 5-20. doi: 10.1104/pp.113.222737

Yuan, Y., and Lee, T. R. (2013). Contact angle and wetting properties. Surf. Sci. Tech. 51, 3-34. doi: 10.1007/978-3-642-34243-1_1

Zhang, J. Y., Broeckling, C. D., Blancaflor, E. B., Sledge, M. K., Sumner, L. W., and Wang, Z. Y. (2005). Overexpression of WXP1 a putative Medicago truncatula AP2 domain containing transcription factor gene increases cuticular wax accumulation and enhances drought tolerance in transgenic alfalfa (Medicago sativa). Plant J. 42, 689-707. doi: 10.1111/j.1365-313X.2005. 02405.x

Zhang, J. Y., Broeckling, C. D., Sumner, L. W., and Wang, Z. Y. (2007). Heterologous expression of two Medicago truncatula putative ERF transcription factor genes WXP1 and WXP2 in Arabidopsis led to increased leaf wax accumulation and improved drought tolerance but differential response in freezing tolerance. Plant Mol. Biol. 64, 265-278. doi: 10.1007/s11103-007-91502doi: 10.1007/s11103-007-9150-2

Conflict of Interest Statement: The authors declare that the research was conducted in the absence of any commercial or financial relationships that could be construed as a potential conflict of interest.

Copyright (C) 2017 Sajeevan, Nataraja, Shivashankara, Pallavi, Gurumurthy and Shivanna. This is an open-access article distributed under the terms of the Creative Commons Attribution License (CC BY). The use, distribution or reproduction in other forums is permitted, provided the original author(s) or licensor are credited and that the original publication in this journal is cited, in accordance with accepted academic practice. No use, distribution or reproduction is permitted which does not comply with these terms. 